\title{
Effects of Essential Oils for Broiler Chicks with Delayed Feeding after Hatching 2. Morphological Development of Small Intestine
}

\author{
Menderes Suicmez ${ }^{1}$, Muzaffer Corduk ${ }^{2}$, Senay Sarica ${ }^{3 *}$
}

${ }^{I}$ Department of Molecular Biology and Genetics, Faculty of Science and Arts, Hitit University, 19040 Çorum, Turkey

${ }^{2}$ Department of Animal Science, Faculty of Agriculture, Ahi Evran University, 40100 Kırşehir, Turkey

${ }^{3}$ Department of Animal Science, Faculty of Agriculture, Gaziosmanpașa University, 60240 Tokat, Turkey

\section{A R T I C LE IN F O}

\section{Research Article}

Received 12 February 2018

Accepted 19 July 2018

Keywords:

Broiler

Delayed feeding

Essential oil

Morphological development

Small intestine

*Corresponding Author:

E-mail: senay.sarica@gop.edu.tr

\section{A B S T R A C T}

The study investigated the effects of oregano- or red pepper-essential oil at delayed feeding $(0,24$ and $48 \mathrm{~h}$ post-hatching) on performance and morphological development of small intestine segments. Female broilers were fed one of 3 rations including a control ration with no essential oil (CONT), the rations added with either oregano essential oil (OEO) or red pepper essential oil (RPEO) at $250 \mathrm{mg} / \mathrm{kg}$ to CONT. A total of 18 chicks from each treatment were used to measure the morphological parameters of the small intestine segments on the $14^{\text {th }}$ day. Prolongation of accessing time to ration significantly decreased the body weights of broilers at $3^{\text {rd }}, 7^{\text {th }}$ and $14^{\text {th }} \mathrm{d}$, feed intake (FI) from 4 to $7 \mathrm{~d}$ and improved feed conversion ratio (FCR) of broilers at the period of 4-7 d. Access to ration for $48 \mathrm{~h}$ post-hatching significantly decreased the body weight gains at the period of 4-7 and 7-14 d, FI from 7 to $14 \mathrm{~d}$ and improved FCR of broilers at the period of 7-14 d. OEO250 ration significantly increased villus height $(\mathrm{VH})$ and villus surface area (VSA) of jejunum (J) and ileum (I) of broilers fed immediately and the IVH and IVSA of broiler accessed to ration for $48 \mathrm{~h}$ post-hatching. VH of duodenum (D), IVH and IVSA of broilers fed for $24 \mathrm{~h}$ post-hatching were significantly increased by RPEO250 ration. OEO250 and RPEO250 rations significantly reduced crypt depth (CD) of D and J of broiler accessed to ration for immediate and DCD of broiler fed for $24 \mathrm{~h}$ post-hatching. OEO250 and RPEO250 rations significantly increased IVH and IVSA and reduced DCD, JCD and ICD of broilers. In conclusion, OEO250 and RPEO250 rations affected positively VH and VSA of I and reduced CDs of small intestine segments of broilers accessed to ration at different times.

DOI: https://doi.org/10.24925/turjaf.v6i10.1347-1352.1847

\section{Introduction}

Broilers have been able to reach a market weight in a short time approximately 40 days of age due to genetic selection (Mahapatra et al., 2017). This situation is directly correlated to the development of especially the small intestine. Early nutrition leads to the morphological development of the small intestine and the increase in the growth performance of broilers. On the other hand, starvation of chicks until $72 \mathrm{~h}$ due to the variation of hatching time and logistics is impaired the morphological development of the small intestine (Prabakar et al., 2016). To alleviate the negative effects of delayed feeding, some researchers have investigated the effects of the early feeding of aromatic plants and their essential oils on the morphological development of the small intestine in recent times (Vidanarachchi et al., 2010; Al-Tememy et al., 2011; Sujatha et al., 2017). Oregano (OEO)- and red pepper- (RPEO) essential oils have antimicrobial activity due to their phenolic compounds (Zarringhalama et al., 2013; Teuchert, 2014).
The present study investigated the effects of the addition of OEO or RPEO to the ration of broiler chicks with immediate, 24- or 48-h post-hatching delayed feeding on the growth performance and morphological development of their small intestine segments from hatch to $14 \mathrm{~d}$.

\section{Materials and Methods}

A total of 432 female broiler (Ross 308) chicks were obtained from a local hatchery. The broiler chicks were randomly allocated to nine groups of similar average weight each of which included three replicates of 16 chicks. The study was conducted in accordance with animal welfare at the Poultry Research Centre of Ankara University.

In the study being a randomized complete block design with a $3 \times 3$ factorial arrangement of treatments, chicks were accessed free to water and ration at three 
different feeding times $(0,24$ and $48 \mathrm{~h}$ post-hatching delayed feeding) and fed one of 3 different rations $(23 \%$ crude protein, $3105 \mathrm{kcal} \mathrm{ME} / \mathrm{kg})$, which were cornsoybean meal based in mash form. The 3 experimental rations were a control ration (CONT) which contain no essential oil and the other rations added with either OEO250 or RPEO at a level of $250 \mathrm{mg} / \mathrm{kg}$ ration to the CONT ration. The rations were prepared as isocaloric and isonitrogenic. The ingredients and nutritional composition of the control ration are given in Table 1.

Table 1 The ingredients and chemical composition of the control ration as fed basis

\begin{tabular}{l|c}
\multicolumn{1}{c|}{ Ingredients } & Amount, g/kg \\
\hline Maize & 549.05 \\
Soybean meal (46\% CP) & 360.87 \\
Fish meal (65\% CP) & 15.00 \\
Sunflower oil & 37.08 \\
Limestone & 11.41 \\
Dicalcium phosphate & 14.89 \\
Salt & 3.50 \\
Vitamin premix* & 2.50 \\
Trace mineral premix** & 1.00 \\
DL-Methionine & 3.20 \\
L-Lysine HCL & 1.50 \\
Total Analysed chemical composition, \% of DM & 1000.00 \\
\multicolumn{2}{c}{ DM }
\end{tabular}

\begin{tabular}{l|c} 
Dry matter & 88.64 \\
Crude protein & 22.94 \\
Crude fiber & 3.10 \\
Crude ash & 5.92 \\
Crude fat & 6.11 \\
Calcium & 0.98 \\
Total phosphorus & 0.73
\end{tabular}

Calculated chemical composition, $\%$ of DM

\begin{tabular}{l|l} 
Metabolizable energy, $\mathrm{kcal} / \mathrm{kg}$ & 3105
\end{tabular}

\begin{tabular}{l|l} 
Crude protein & 23.01
\end{tabular}

Calcium $\quad 1.01$

Available phosphorus $\quad 0.45$

\begin{tabular}{l|r} 
Lysine & 1.35
\end{tabular}

\begin{tabular}{l|l} 
Trytophan & 0.25
\end{tabular}

Arginine $\quad 1.49$

Methionine $\quad 0.62$

\begin{tabular}{l|l} 
Methionine+cystine & 0.99
\end{tabular}

\begin{tabular}{l|l} 
Threonine & 0.86 \\
\hline
\end{tabular}

*Vitamin premix provided (per kg of ration): $3600 \mu \mathrm{g}$ of trans-retinol, $15.0 \mu \mathrm{g}$ of cholecalciferol, $50 \mathrm{mg}$ of $\alpha$-tocopherol acetate, $5 \mathrm{mg}$ of vitamin $\mathrm{K}_{3}, 3 \mathrm{mg}$ of vitamin $\mathrm{B}_{1}, 6 \mathrm{mg}$ of vitamin $\mathrm{B}_{2}, 5 \mathrm{mg}$ of vitamin $\mathrm{B}_{6}$, $0.03 \mathrm{mg}$ of vitamin $\mathrm{B}_{12}, 25 \mathrm{mg}$ of niacin, $12 \mathrm{mg}$ of Ca-D-pantothenate, 1 $\mathrm{mg}$ of folic acid, $0.05 \mathrm{mg}$ of D-biotin, $2.5 \mathrm{mg}$ of apo-carotenoic acid ester, $400 \mathrm{mg}$ of choline chloride.

**Trace mineral premix provided (per $\mathrm{kg}$ of ration): $80 \mathrm{mg}$ of $\mathrm{Mn}, 60$ $\mathrm{mg}$ of $\mathrm{Fe}, 60 \mathrm{mg}$ of $\mathrm{Zn}, 5 \mathrm{mg}$ of $\mathrm{Cu}, 0.20 \mathrm{mg}$ of $\mathrm{Co}, 1 \mathrm{mg}$ of I, $0.15 \mathrm{mg}$ of Se.

Before experimental diet formulation, nutrient values (dry matter, crude protein, crude fat, starch and total sugar) of feed ingredients were analyzed according to the methods of AOAC (2007). The rations were formulated to meet minimum requirements (NRC 1994) standards for all ingredients. The essential oils of the red pepper (Capsicum annuum L.) (RPEO) and the oregano (Origanum onites spp) (OEO) were obtained from the samples by steam-distillation using Clevenger distillation apparatus according to U.S. Pharmacopoeia methods (1995). The major two phenolics (carvacrol and thymol) of these essential oils were determined by GC/MS (Shimadzu, QP2010-Ultra Model).

The carvacrol and thymol content of OEO were 84.02 and $1.78 \%$, respectively. The quercetin and luteolin content of RPEO also were 20.65 and $8.80 \%$, respectively. OEO or RPEO were added to an amount of sunflower oil and then the mixture was added to corn.

The broiler chicks were kept in wire cages with nipple drinkers under standard environmental conditions with the controlled temperature and humidity throughout the experiment. The lighting regime was 23 hours light and 1hour darkness in the experiment. Ambient temperature was gradually decreased from $32^{\circ} \mathrm{C}$ on d 0 to $25^{\circ} \mathrm{C}$ on $\mathrm{d} 14$.

A total of 18 female broiler chicks from each treatment (six chicks from each replicate) that were nearest to the average weight were selected and slaughtered by severing the jugular vein and measured the morphological parameters of the small intestine segments (duodenum, jejunum and ileum) on the $14^{\text {th }}$ day.

To analyse the morphological structure of the small intestine, the intestinal content was firstly removed. Then, the samples were flushed with $0.9 \%$ (wt/vol) $\mathrm{NaCl}$ and handled according to Uni et al. (2003). Histological examinations were carried out using a computer-assisted image analysis according to the method of Uni et al. (1998). Villus height (VH) was measured from the tip of villus to the crypt-villus junction, whereas villus width (VW) was defined as the distance from the outside epithelial edge along a line passing through the vertical midpoint of the villus. Villus surface area (VSA) was calculated from the villus height and width at half height.

Statistical Analysis

Linear Model using the SPSS (17.0) ${ }^{\circledR}$ statistic package (2007) was applied to data with a model including OEO250 or RPEO250 and accessing time to ration and interaction between essential oils and accessing time to ration. Significant differences between treatment means were separated using Duncan's multiple range test (1955). All statements of significance were based on $\mathrm{P}<0.05$.

\section{Results and Discussion}

\section{Growth Performance}

Body weights of broilers at $3^{\text {rd }}, 7^{\text {th }}$ and $14^{\text {th }}$ days were not affected by RTs (Table 2). On the other hand, prolongation of accessing time to ration from immediate to 24 and $48 \mathrm{~h}$ post-hatching significantly decreased the body weights of broilers at $3^{\text {rd }}, 7^{\text {th }}$ and $14^{\text {th }}$ days $(\mathrm{P}<0.01)$. Body weight gains of broilers during the period of 4-7 and 7-14 days were not significantly influenced by RTs. Access to ration for $48 \mathrm{~h}$ post-hatching significantly decreased the body weight gains at the period of 4-7 and 7-14 days compared to immediate and $24 \mathrm{~h}$ post-hatching $(\mathrm{P}<0.01)$. These results showed that broiler chickens could not compensate for the retardation of their body weight gain during the period of 4-7 and 7-14 $d$ when chickens accessed to ration for $48 \mathrm{~h}$ post-hatch. Results of this study related to body weight gain are in agreement with the findings of Bigot et al. (2003) who reported that feed deprivation for $2 \mathrm{~d}$ post hatching of broilers was not sufficient to compensate for the retardation of body 
weight gain and reduced. Moreover, Barreto et al. (2008) showed that there was not any significant difference between the control ration and ration supplemented with red pepper extract at $200 \mathrm{ppm}$ in terms of the body weight gain of broilers throughout $21 \mathrm{~d}$. Prolongation of accessing time from immediate to 24 and $48 \mathrm{~h}$ posthatching to ration of broilers significantly reduced feed intake and improved feed conversion ratio (FCR) of broilers at the period of 4-7 d $(\mathrm{P}<0.01)$. Moreover, delaying feeding for $48 \mathrm{~h}$ post-hatching significantly decreased feed intake and improved FCR of broilers at the period of 7-14 $\mathrm{d}$ compared to accessing time to ration for immediate and $24 \mathrm{~h}$ post-hatching $(\mathrm{P}<0.01)$. This result is not in agreement with the finding of Al-Harthi (2002) indicated that the dietary supplementation of $0.2 \%$ red pepper extract resulted in the best growth and FCR compared to the control group. RTs did not significantly affect the growth performance through all experimental period (Table 2). As a result, it can be said that their any significant effect will not show when essential oils were supplemented to ration at insufficient rates (Lee et al., 2003; Cross et al., 2007).

Table 2 Effects of treatments on the performance parameters of broiler chicks $(n=3)$

\begin{tabular}{|c|c|c|c|c|c|c|c|c|c|c|c|}
\hline \multirow[t]{2}{*}{ RT } & \multirow[t]{2}{*}{ AT } & \multicolumn{4}{|c|}{ Body weights, g/day } & \multicolumn{2}{|c|}{$\begin{array}{l}\text { Body weight } \\
\text { gains, g/day }\end{array}$} & \multicolumn{2}{|c|}{$\begin{array}{c}\text { Feed intake, } \\
\text { g/day }\end{array}$} & \multicolumn{2}{|c|}{$\begin{array}{c}\text { Feed conversion } \\
\text { ratio, } g / g\end{array}$} \\
\hline & & Initial & 3. & 7. & 14. & $4-7$ & $7-14$ & $4-7$ & $7-14$ & $4-7$ & $7-14$ \\
\hline \multirow{3}{*}{ CONT } & Immediate & 50.00 & 83.95 & 174.40 & 430.70 & 22.62 & 36.62 & 28.85 & 49.43 & 1.276 & 1.350 \\
\hline & $24 \mathrm{~h}$ & 48.60 & 73.34 & 159.00 & 397.90 & 21.41 & 34.13 & 26.41 & 46.67 & 1.234 & 1.368 \\
\hline & $48 \mathrm{~h}$ & 49.50 & 61.10 & 133.50 & 368.90 & 18.10 & 33.64 & 21.29 & 42.79 & 1.176 & 1.272 \\
\hline \multirow{3}{*}{ OEO250 } & Immediate & 50.00 & 79.24 & 159.60 & 385.60 & 20.09 & 32.28 & 26.51 & 43.26 & 1.320 & 1.340 \\
\hline & $24 \mathrm{~h}$ & 48.90 & 72.86 & 158.00 & 395.90 & 21.29 & 33.98 & 25.28 & 46.02 & 1.188 & 1.354 \\
\hline & $48 \mathrm{~h}$ & 49.25 & 61.29 & 137.10 & 367.10 & 18.95 & 32.85 & 21.91 & 43.19 & 1.156 & 1.315 \\
\hline \multirow{3}{*}{ RPEO250 } & Immediate & 50.00 & 83.38 & 173.70 & 410.30 & 22.59 & 33.79 & 28.73 & 47.56 & 1.272 & 1.408 \\
\hline & $24 \mathrm{~h}$ & 49.00 & 71.64 & 156.10 & 396.90 & 21.12 & 34.39 & 24.36 & 47.59 & 1.153 & 1.384 \\
\hline & $48 \mathrm{~h}$ & 49.40 & 61.52 & 138.90 & 363.90 & 19.34 & 32.15 & 22.39 & 43.70 & 1.158 & 1.359 \\
\hline SEM & & & 1.67 & 3.81 & 9.59 & 0.65 & 1.06 & 0.90 & 1.65 & 0.023 & 0.018 \\
\hline \multirow{3}{*}{ RT } & CONT & & 72.79 & 155.60 & 399.20 & 20.71 & 34.79 & 25.52 & 46.30 & 1.232 & 1.331 \\
\hline & OEO250 & & 71.13 & 151.60 & 382.80 & 20.11 & 33.04 & 24.57 & 44.16 & 1.222 & 1.337 \\
\hline & RPEO250 & & 72.18 & 156.20 & 390.40 & 21.02 & 33.45 & 25.16 & 46.28 & 1.197 & 1.384 \\
\hline \multirow{3}{*}{ AT } & Immediate & & $82.19^{a}$ & $169.20^{\mathrm{a}}$ & $408.90^{\mathrm{a}}$ & $21.76^{\mathrm{a}}$ & $34.23^{\mathrm{a}}$ & $28.03^{\mathrm{a}}$ & $46.75^{\mathrm{a}}$ & $1.288^{\mathrm{a}}$ & $1.366^{\mathrm{a}}$ \\
\hline & $24 \mathrm{~h}$ & & $72.61^{b}$ & $157.70^{\mathrm{b}}$ & $396.90^{b}$ & $21.27^{\mathrm{a}}$ & $34.17^{\mathrm{a}}$ & $25.35^{\mathrm{b}}$ & $46.76^{\mathrm{a}}$ & $1.192^{b}$ & $1.369^{\mathrm{a}}$ \\
\hline & $48 \mathrm{~h}$ & & $61.30^{c}$ & $136.50^{c}$ & $366.60^{c}$ & $18.80^{\mathrm{b}}$ & $32.88^{\mathrm{b}}$ & $21.86^{\mathrm{c}}$ & $43.23^{\mathrm{b}}$ & $1.163^{\mathrm{c}}$ & $1.315^{\mathrm{b}}$ \\
\hline SEM & & 0.241 & 0.96 & 2.20 & 5.54 & 0.38 & 0.61 & 0.52 & 0.95 & 0.019 & 0.011 \\
\hline \multicolumn{2}{|l|}{$\mathrm{P}$ value } & & NS & NS & NS & NS & NS & NS & NS & NS & NS \\
\hline \multicolumn{2}{|l|}{ AT } & & $* *$ & $* *$ & $* *$ & $* *$ & $* *$ & $* *$ & $*$ & $* *$ & $* *$ \\
\hline \multicolumn{2}{|l|}{$\mathrm{RT} \times \mathrm{AT}$} & & NS & NS & NS & NS & NS & NS & NS & NS & NS \\
\hline
\end{tabular}

${ }_{\text {a,b,c }}$ Value within a column not sharing a common superscript differ significantly ( $\left.* \mathrm{P}<0.05 ; * * \mathrm{P}<0.01\right)$; Different letter superscripts indicate means that were significantly different $(\mathrm{P}<0.05)$, RT: ration treatments; AT: accessing time to ration; CONT: no contained essential oil; OEO250: oregano essential oil, $250 \mathrm{mg} / \mathrm{kg}$; RPEO250: red pepper essential oil, $250 \mathrm{mg} / \mathrm{kg}$; NS: Not Significant; SEM: Standard error of the means

\section{Morphological Development of Small Intestine Segments}

The effects of RTs and accessing time ATs to ration on the morphological development of duodenum, jejunum and ileum of small intestine in broilers on the $14^{\text {th }}$ day were given in Table 3.

RTs significantly affected the villus height (DVH) $(\mathrm{P}<0.01)$ and the villus surface area (DVSA) $(\mathrm{P}<0.001)$ of duodenum. The CONT ration significantly increased DVH and DVSA compared with the OEO250 and RPE0250 rations. Moreover, access immediately to ration also enhanced DVH and DVSA of broilers $(\mathrm{P}<0.001)$.

There is an interaction between RTs and ATs to ration in terms of the DVH, DVSA and DCD of broilers on the $14^{\text {th }}$ day (Table 3 ). The DVH and DVSA of the chickens fed the CONT and OEO250 rations were increased $(\mathrm{P}<0.001)$ by feeding immediately. On the other hand, the DVH and DVSA of broilers fed the RPEO250 ration were enhanced by $24 \mathrm{~h}$ post-hatching $(\mathrm{P}<0.001)$.

As investigated the interaction between ATs to ration and RTs, the DVH and DVSA of broilers accessed to ration immediately were increased $(\mathrm{P}<0.001)$ by feeding the CONT ration. Result of this study did not similar with the findings of Akbarian et al. (2013) and Teuchert (2014) who found no significant differences between the control ration and ration supplemented with the oregano extract on villus height of duodenum of broilers. The DVH of broiler fasted for $24 \mathrm{~h}$ post-hatching was increased by the RPE0250 ration $(\mathrm{P}<0.001)$. The DVSA of broilers fasted for 24 or $48 \mathrm{~h}$ post-hatching, respectively, was increased $(\mathrm{P}<0.001)$ by the CONT and, CONT and OEO250 rations, respectively.

The crypt depth (CD) of duodenum was significantly decreased by OEO250 and RPEO250 rations $(\mathrm{P}<0.001)$. DCD of broilers was significantly increased by prolongation of accessing time to ration $(\mathrm{P}<0.001)$.

There is a significant interaction between RTs and ATs in terms of DCD of chickens $(\mathrm{P}<0.001)$. The DCD of broilers fed CONT ration was significantly reduced by access to ration for immediate and $48 \mathrm{~h}$ post-hatching $(\mathrm{P}$ $<0.001)$. On the other hand, DCDs of broilers fed $\mathrm{OEO} 250$ and RPEO250 rations were significantly decreased by feeding for immediate and $24 \mathrm{~h}$ posthatching $(\mathrm{P}<0.001)$. 
Table 3 The effects of different reach times to the rations containing different essential oil on the development of small intestine morphology of broilers on the $14^{\text {th }}$ day

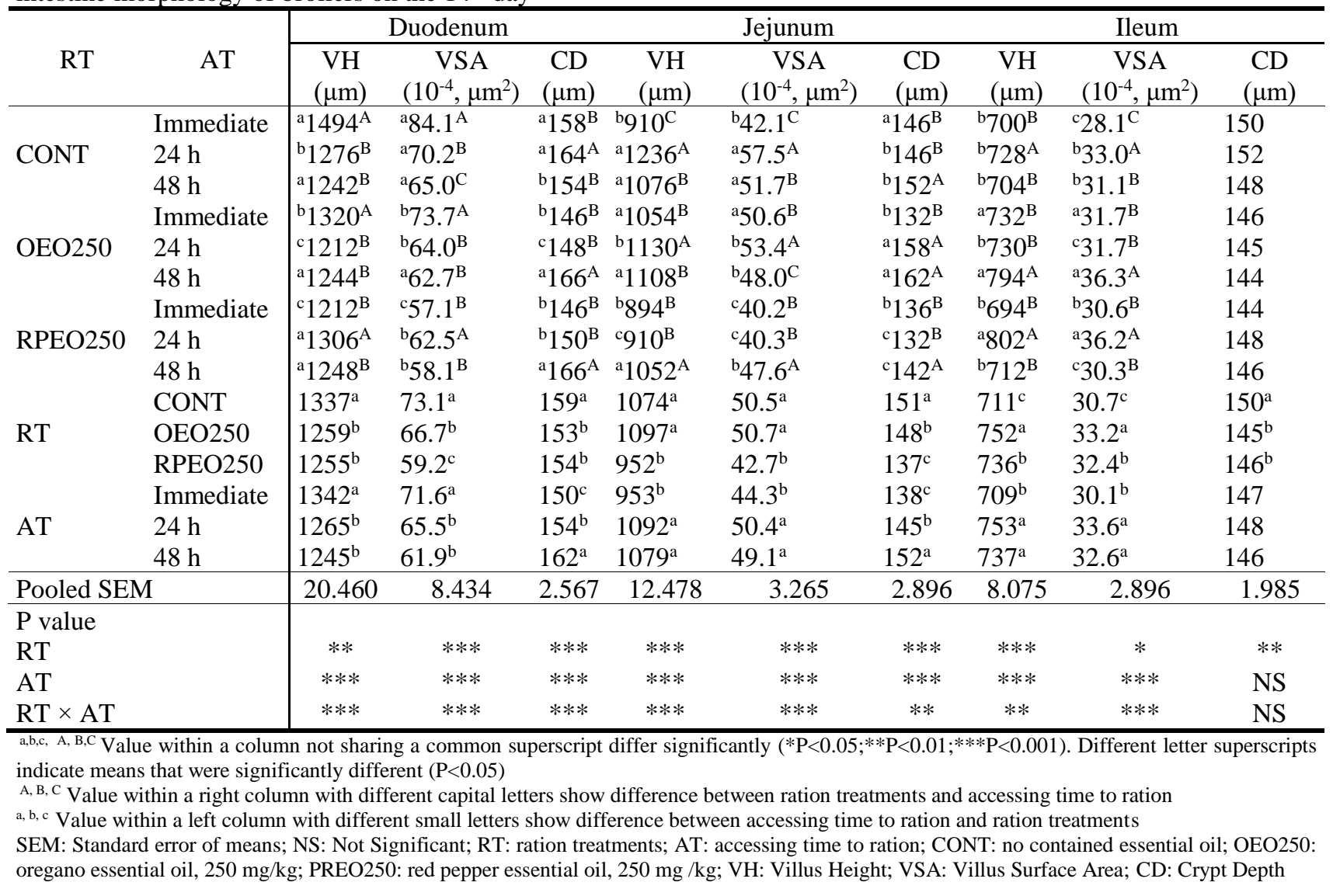

There is also a significant interaction between ATs and RTs in terms of DCD of broiler $(\mathrm{P}<0.001)$. DCDs of chickens fed immediate or $24 \mathrm{~h}$ post-hatching were significantly decreased by OEO250 and RPEO250 rations $(\mathrm{P}<0.001)$. On the other hand, DCD of broilers accessed to ration for $48 \mathrm{~h}$ post-hatching was significantly reduced by CONT ration $(\mathrm{P}<0.001)$.

This finding did not in agreement with the results of Akbarian et al. (2013) and Teuchert (2014) who reported that the plant extracts did not affect any significant effect on the crypt depth of duodenum in broilers.

The essential oils and their phenolic compounds have an antibacterial activity due to combating pathogenic bacteria in the small intestine of poultry (Ayman et al. 2016). As a result of this, the total pathogenic bacteria in the intestinal wall, the production of toxic compounds and the damage to intestinal epithelial cells like deeper crypts were decreased by the essential oils (Ghazanfari et al., 2014).

The CONT and OEO250 rations significantly enhanced the villus height $(\mathrm{JVH})$ and villus surface area (JVSA) of jejunum of broilers compared to the RPEO250 ration $(\mathrm{P}<0.001)$. In addition, access to ration for 24 and $48 \mathrm{~h}$ post-hatch significantly increased JVH and JVSA of broilers compared with immediately access $(\mathrm{P}<0.001)$.

There is a significant interaction $(\mathrm{P}<0.001)$ between RTs and ATs to ration in terms of the villus height (JVH), villus surface area (JVSA) and crypt depth (JCD) of jejunum of broilers on the $14^{\text {th }}$ day (Table 3 ). The JVH and JVSA of broilers fed the CONT and OEO250 rations were increased by feeding after $24 \mathrm{~h}$ post-hatching
$(\mathrm{P}<0.001)$. Moreover, the JVH and JVSA of chickens fed with the RPEO250 ration were enhanced by feeding after 48 h post-hatching $(\mathrm{P}<0.001)$.

The interaction between ATs to ratio and RTs, the JVH and JVSA of broilers immediately accessed to ration were the highest $(\mathrm{P}<0.001)$ when broilers were fed the OEO250 ration.

This finding agrees with the results of Jamroz et al. (2006) who reported that the dietary supplementation of a plant extract blend caused to major increase in JVH of chickens. Sujatha et al. (2017) pointed out villus height of jejunum of chicks fed with neem supplementation was significantly increased compared to that of control chicks.

On the contrary, the results related to the JVH did not in agreement with the findings of Teuchert (2014) who found no significant differences between the control ration and ration supplemented with an oregano extract on villus height of jejunum in broilers.

On the other hand, the JVH and JVSA of broilers fasted for $24 \mathrm{~h}$ post-hatching were increased by the CONT ration $(\mathrm{P}<0.001)$. There are no differences among the rations in terms of JVH of chickens accessed to ration for $48 \mathrm{~h}$ post-hatching. JVSA of chickens accessed to ration for $48 \mathrm{~h}$ post-hatching was significantly increased by the CONT ration $(\mathrm{P}<0.001)$.

The JCD of broilers was significantly decreased by OEO250 and RPEO250 rations $(\mathrm{P}<0.001)$. Prolongation of accessing time to ration significantly increased JCD of broilers at 14 days $(\mathrm{P}<0.001)$.

There is a significant interaction between RTs and ATs in terms of JCD of broilers $(\mathrm{P}<0.01)$. JCDs of 
broilers fed CONT or RPEO250 rations were significantly reduced by access to ration for immediate or $24 \mathrm{~h}$ posthatching $(\mathrm{P}<0.01)$. On the other hand, JCD of broilers fed OEO250 ration was significantly reduced by feeding immediately $(\mathrm{P}<0.01)$.

There is also a significant interaction between ATs and RTs in terms of JCD of broilers $(\mathrm{P}<0.01)$. JCD of broilers accessed to ration immediately was significantly decreased by OEO250 and RPEO250 rations $(\mathrm{P}<0.01)$. On the other hand, JCD of chickens fed after 24 or $48 \mathrm{~h}$ post-hatching was significantly reduced by RPEO 250 ration $(\mathrm{P}<0.01)$.

This result did not in agreement with the findings of Garcia et al. (2007), Akbarian et al. (2013) and Teuchert (2014) who pointed out supplementation of a dietary plant extract blend or oregano extract to ration did not influence the JCD of chickens.

Feeding OEO250 and RPEO250 rations significantly increased IVH and IVSA of broilers compared to those of broilers fed CONT ration. Moreover, prolongation of accessing time to ration from immediate to 24 and $48 \mathrm{~h}$ post-hatching significantly increased IVH and IVSA of broilers $(\mathrm{P}<0.001)$.

This finding is in agreement with the results of Skoufos et al. (2016) who reported that the supplementation of oregano essential to ration significantly increased IVH compared to the CONT group. On the contrary, Teuchert (2014) found that oregano extract supplementation to ration did not influence IVH of broilers compared to the control ration.

There is a significant interaction between RTs and ATs in terms of IVH $(\mathrm{P}<0.01)$ and IVSA $(\mathrm{P}<0.001)$ of broilers. IVHs of broilers fed CONT and REPO250 rations were significantly increased by feeding after $24 \mathrm{~h}$ post-hatching $(\mathrm{P}<0.01)$. On the other hand, IVH $(\mathrm{P}<0.01)$ and IVSA $(\mathrm{P}<0.001)$ of broilers fed OEO250 ration was significantly enhanced by access to ration for $48 \mathrm{~h}$ posthatching.

There is also a significant interaction between ATs and RTs in terms of IVH $(\mathrm{P}<0.01)$ and IVSA $(\mathrm{P}<0.001)$ of broilers. IVH of broilers fed immediately or $48 \mathrm{~h}$ posthatching was significantly increased by OEO250 ration $(\mathrm{P}<0.01)$. On the other hand, IVH $(\mathrm{P}<0.01)$ and IVSA $(\mathrm{P}<0.001)$ of broilers accessed to ration for $24 \mathrm{~h}$ posthatching was significantly enhanced by RPEO250 ration. The results in this study indicate that feeding essential oils enriched in phenolic compounds due to their high antimicrobial activities increased villus height that is associated with enhanced digestive and absorptive surface area and nutrient absorption (Ghazanfari et al., 2015).

OEO250 and RPEO250 rations significantly decreased ICD of broilers compared to that of broilers fed CONT ration $(\mathrm{P}<0.01)$. On the other hand, ATs did not influence ICD of broilers.

Oregano- and red pepper- essential oils and their phenolic compounds reduced the microbial load of pathogenic bacteria and their toxins on the small intestine. As a result of this, the crypt depths of small intestine segments were decreased, which prevented the degeneration of absorptive epithelial cells (AlMashhadani et al., 2013).

\section{Conclusion}

RTs did not significantly affect the growth performance through all experimental period. Prolongation of accessing time to ration from immediate to 24 and $48 \mathrm{~h}$ post-hatching significantly decreased the body weights of broilers at $3^{\text {rd }}, 7^{\text {th }}$ and $14^{\text {th }}$ days, feed intake from 4 to $7 \mathrm{~d}$ and improved feed conversion ratio (FCR) of broilers at the period of 4-7 d. Access to ration for $48 \mathrm{~h}$ post-hatching significantly decreased the body weight gains at the period of 4-7 and 7-14 days, feed intake from 7 to $14 \mathrm{~d}$ and improved FCR of broilers at the period of 7-14 d compared to accessing time to ration for immediate and $24 \mathrm{~h}$ post-hatching. The supplementation of oregano- and red pepper-essential oils to ration at 250 $\mathrm{mg} / \mathrm{kg}$ level affected positively the villus height and villus surface area of ileum and reduced crypt depths of small intestine segments of broiler accessed to ration at different times.

\section{References}

Akbarian A, Golian A, Kermanshahi H., Farhoosh R, Raji AR, De Smet S, Michiels J. 2013. Growth performance and gut health parameters of finishing broilers supplemented with plant extracts and exposed to daily increased temperature. Spanish Journal of Agricultural Research, 11 (1): 109-119.

Al-Harthi MA. 2002. Performance and carcass characteristics of broiler chicks as affected by different dietary types and levels of herbs, and spices as non-classical growth promoters. Egypt. Poult.Sci. 22: 325-343.

Al-Mashhadani EH, Al-Tememy SA, Al-Jaff FK, AlMashhadani HE. 2013. Effect of supplementing broiler diet with anise and thyme essential oils on histological changes of small intestine. Egypt Poultry Science, 33 (1): 249-259.

Al-Tememy HSA, Al-Jaff FK, Al-Mashhadani EH, Hamodi SJ. 2011. Histological effect of inclusion different levels of coriander oil in broiler diet on small intestine. Diyala Agricultural Sciences Journal. 3 (2): 1-11.

Ayman MHA, Mourad HS El-S, Mostafa MME. 2016. Effect of peppermint extracts inclusion in broiler chick diet on chick performance, plasma constitutents, carcass traits and some microbial populations, enyzmatic activity and histological aspects of small intestine. Asian Journal of Animal and Veterinary Advance, 11: 441-451.

AOAC. 2007. Association of Official Analytical Chemistry Official methods of analysis. $18^{\text {th }} \mathrm{Ed}$. AOAC International, W.D.C., USA, 2007.

Barreto MSR, Menten JFM, Racanicci AMC, Pereire PWZ, Rizzo PV. 2008. Plant extracts used as growth promoters in broilers. Revista Brasileira de Ciencia Avicola 10: 109-115.

Bigot K, Mignon-Grasteau S, Picard M, Tesseraud S. 2003. Effects of delayed feed intake on body, intestine and muscle development in neonate broilers. Poultry Science. 82: 781788.

Cross DE, McDevitt RM, Hillman K, Camovic TA. 2007. The effects of herbs and their associated essential oils on performance, dietary digestibility and gut microflora in chickens from 7 to 28 days of age. Br. Poult. Sci. 48: 496506.

Duncan DB. 1955. Multiple range test and multiple F tests. Biometrics, 11: 1-42.

Garcia V, Catala-Gregori P, Hernandez F, Megias MD, Madrid J. 2007. Effect of formic acid and plant extracts on growth, nutrient digestibility, intestine mucosa morphology and meat yield of broilers. Journal of Applied Poultry Research, 16: 555-562. 
Ghazanfari S, Adib Moradi M, Mahmoodi Bardzardi M. 2014. Intestinal morphology and microbiology of broiler chicken fed diets containing myrtle (Myrtus communis) essential oil supplementation. Iranian Journal of Applied Animal Science, 4 (3): 549-554.

Ghazanfari S, Mohammadi Z, Adib MM. 2015. Effects of coriander essential oil on the performance, blood characteristics, intestinal microbiota and histological of broilers. Brazilian Journal of Poultry Science, 17 (4): 419426.

Jamroz D, Wertelecki T, Houszka M, Kamel C. 2006. Influence of diet type on the inclusion of plant origin active substances on morphological and histochemical characteristics of the stomach and jejunum walls in chicken. Journal of Animal Physiology and Animal Nutrition, 90 (5-6): 255-268.

Lee KW, Everts H, Kappert HJ, Frehner M, Losa R, Beynen AC. 2003. Effects of dietary essential oil components on growth performance, digestive enzymes and lipid metabolism in female broiler chickens. Br. Poult. Sci. 44: 450-457.

Mahapatra S, Srinivasan G, Rajini AR, Gowri AM. 2017. Effect of early post-hatch nutrition on production performance of commercial broiler chicken. Indian Journal of Animal Research, 51 (2): 291-295.

NRC. 1994. Nutrient Requirements of Poultry. National Academic Press. Washington, D.C.

Prabakar G, Pavulraj S, Shanmuganathan S, Kirubakaran A, Mohana N. 2016. Early nutrition and its importance in poultry: a review. Indian Journal of Animal Nutrition, 33 (3): 245-252.

Skoufos I, Giannenas I, Tontis D, Bartzanas T, Kittas C, Panagakis P, Tzora A. 2016. Effects of oregano essential oil and attapulgite on growth performance, intestinal microbiota and morphometry in broilers. South African Journal of Animal Science, 46 (1): 77-88.
SPSSWIN. 2007. SPSS for Windows 6.1.4. SPSSWIN. Istanbul, Turkey.

Sujatha T, Abhinaya S, Sunder J, Thangapandian M, Kundu A. 2017. Efficacy of early chick nutrition with Aloe vera and Azardirachta indica on gut health and histomorphometry in chicks. Veterinary World, 10 (1): 569-573.

Teuchert N. 2014. Comparison of production parameters, gut histology, organ weights and portion yields of broilers supplemented with Ateli plus ${ }^{\circledR}$. Master Thesis. http://scholar.sun.ac.za.

United States Pharmacopeia and the National Formulary. 1995. The United States Pharmacopeia: The National Formulary. United States Pharmacopeial Convention, Michigan University. USA.

Uni Z, Ganot S, Sklan D. 1998. Posthatch development of mucosal function in the broiler small intestine. Poultry Science, 77: 75-82.

Uni Z, Smirnov A, Sklan D. 2003. Pre- and posthatch developmentof goblet cells in the broiler small intestine: Effect of delayed access to feed. Poultry Science, 82: 320 327.

Vidanarachchi JK, Elangovan AV, Mikkelsen LL, Chocht M, Iji PA. 2010. Effect of some plant extracts on growth performance, intestinal morphology, microflora composition and activity in broiler chickens. Animal Production Science, 50: 880-889.

Zarringhalama M, Zaringhalamb J, Shadnoushc M, Safaeyand F, Tekiehb E. 2013. Inhibitory effect of black and red pepper and thyme extracts and essential oils on Enterohemorrhagic Escherichia coli and DNase activity of Staphylococcus aureus. Iranian Journal of Pharma Research, 12 (3): 363369. 